\title{
Estimating the profitability of the British east coast main line
}

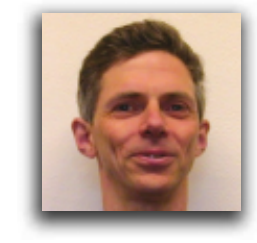

Nigel G. Harris BSC, PhD

Managing Director, The Railway Consultancy Ltd, London, UK

\begin{abstract}
Successful railway franchising requires both bidders and tendering authority to have a good understanding of the underlying economics of that part of the railway. However, an earlier franchise contract for Britain's east coast main line franchise was terminated early by the government in 2006, while a more recent franchisee has recently passed the franchise back to the government, having suffered unduly during the recession of 2008-2009. Both bidders made very significant (and, it would appear, unsustainable) promises to government in terms of paying a premium to operate the services concerned, but such premia inevitably derive from the competitive situation of franchising. This paper sets out some indicative analysis of train operator profitability in Britain which provides some guidance as to the appropriate level of premium for this - and other - franchises, with some more general conclusions.
\end{abstract}

\section{Introduction}

Amidst all the anticipation surrounding the possibility of constructing new high-speed rail lines in Britain, it is easy to lose sight of the fundamental economics of the rail industry. This paper sets out to do two things. First, it uses data from the British mainline railway train operating companies to estimate the breakeven trainload; although the results are country-specific, they should provide guidance for railway planners worldwide. Second, using the understanding of profitability that this analysis brings, the paper explores why two successive franchisees for one particular route have failed.

A number of railway systems around the world have been brought into the private sector through a franchising model. In Britain, following the privatisation of British Rail, specified passenger services were grouped and let by the government as franchises, typically for seven years. A few franchises of potentially profitable routes were let to the bidder offering the highest premium payment to operate the designated train services. Most franchises, however, required subsidy, and the bidder undertaking to operate the service with the lowest subsidy was successful.

The east coast main line (ECML) linking London and Edinburgh via York and Newcastle, and with a branch from Doncaster to Leeds, is one of Britain's key rail routes. Electrified in 1991, and designated as a Trans-European Network route, its services include high-speed passenger services operating at $225 \mathrm{~km} / \mathrm{h}$ and diesel-hauled freight operating at half that speed. As the core route between Peterborough and York is largely only doubletrack, the mix of train types and speeds means that the line is nearing capacity. Given Britain's high rail fares, and the level of capacity utilisation, this means that the ECML is one of the most profitable lines in Britain.
The ECML's high-speed passenger services were let as the east coast franchise in 1996 (Harris and Godward, 1997). Services comprised around 100 trains per day on the two key routes to Edinburgh and Leeds, with a few trains extended off the network, such as to Glasgow, Aberdeen and Skipton. The services were tendered as a group, leaving any operator to spread costs across different services.

Commercial freedom in franchises is tempered by government requirements to maintain basic frequencies to all destinations previously served. In the intercity sector, bidders' strategies generally focused on using assets more intensively, and in using yield management techniques to increase revenues. Although winners Sea Containers promised a subsidy profile which reduced to zero in 2003 , the picture was somewhat complicated by changes to the financial support regime for the infrastructure authority Network Rail. These changes were implemented after a derailment at Hatfield in 2000, after which there were major increases in maintenance and renewals expenditure (ORR, 2007). Sea Containers' subsidiary GNER developed a service widely recognised as being of high quality, and based on high standards of customer care, although there were no doubt cost implications of this.

As franchising developed, winning bids generally had to promise ever-larger improvements in business turnround (Harris, 1997). In 2005, as part of the second period of franchising, GNER undertook to provide premia to the British government of no less than $£ 1.3$ billion in net present value (NPV) terms over the ten-year franchise period (Gourvish, 2008), based largely on aggressive revenue growth assumptions perhaps encouraged by the Treasury's desire to reduce net expenditure on the railways. However, improved resource utilisation was also expected after the electrification of a short section of line in Yorkshire. By 2005, however, 
it became clear that revenue (although growing) was falling short of their requirements (TAS, 2008). When GNER's parent company Sea Containers faced financial problems, the Department for Transport stepped in and terminated the franchise, offering another competition for it.

Four groups submitted bids, although the winning bid was not the highest, which government officials decided was undeliverable. Instead, the tender was awarded to the National Express Group. Having recently lost a number of franchises, they had recruited ex-Strategic Rail Authority boss Richard Bowker to reinvigorate their business, and this included a bid for the east coast franchise of $£ 1.5$ billion NPV over 7 years, even more aggressive than the failed GNER business plan. Broadly speaking, premium payments were to rise from $£ 1$ million per week in the early years to over $£ 5$ million per week by 2015. This was to be achieved by improved yield management, offpeak frequency increases in the key London-Leeds service to half-hourly, and addition of a few trains to further offline destinations including Lincoln.

These proposed premium payments were significantly in excess of those relating to other InterCity franchises. Although direct comparisons are difficult because of the inclusion in some InterCity franchises of connecting local services and the somewhat arbitrary allocation of infrastructure costs between franchises, it should be noted that current (2010) premium payments on the east coast are around $£ 0.04$ per passenger-mile (DfT, 2012). Other InterCity franchises have payments around zero, while cross country and west coast are in receipt of subsidies of around $£ 0 \cdot 10$ per passenger-mile (TAS, 2008), the latter partly reflecting west coast main line upgrade costs.

The international financial recession of 2007-2009 put the National Express premium payments under severe test. Although the actual number of passenger journeys made held up reasonably well at a relatively high 225 per train ( $\approx 55 \%$ of capacity), revenues are understood to have fallen by around $15 \%$, as business passengers down-traded to standard class and full-fare standard class passengers sought bargains among the cheaper book-ahead fares. The franchise began to lose significant sums of money, a loss of $£ 20$ million in the first 6 months of 2009 being reported. Owning group National Express therefore indicated to the government that, when its cash reserves ran out, the franchise would be returned (even though this meant forfeiting bonds of $£ 72$ million). This occurred on 20 November 2009; the franchise had failed again.

This paper is not about the exact way in which the line is franchised, and what subsidy or premium a bidder might choose to offer in terms of the risk they may wish to bear, or the level of desire they have for winning a particular franchise. Rather, it seeks to understand the fundamental economics of the line, and what would be an appropriate level of subsidy or premium. The situation has become more complicated because the government is now making additional direct payments to Network Rail for infrastructure works. These extra payments are to supplement the funds reaching NR through train operators, and somewhat defray the possible access charges which might be levied against the franchise. However, it still appears that the east coast route is profitable in a long-term economic perspective. The paper therefore moves on to an analysis of train operator finances, which casts some light on the innate profitability of this - and other routes in the British context.

\section{Analysis}

A (presumably unintended and rarely available) side-effect of the creation of 25 franchises with the privatisation of Britain's railways in 1994 was the ability to undertake statistical analysis on a reasonably significant sample, even if data are sometimes inconsistent. Previously unpublished research by the author had examined the relationship between train operator profitability and average train load. If revenues per passenger $\mathrm{km}$ and costs per train $\mathrm{km}$ were constant, the relationship examined would, of course, be linear; that it is not suggests that there is indeed some interesting variation. With railway operations having semi-fixed costs such as train drivers (in addition to the much larger fixed costs of infrastructure), the hypothesis was that busier trains would enable operators to spread their direct costs between more passengers, and hence to be more profitable. Direct costs are taken to include train crew and station staff (typically $\approx 20 \%$ of turnover), rolling stock leasing $(\approx 15 \%)$, diesel fuel/electricity for traction $(\approx 5 \%)$, and track access charges to reimburse Network Rail for infrastructure maintenance and operation (20-40\%) (TAS, 2008). There was indeed some (albeit weak) evidence to support this contention.

In the light of the recurring problems on the ECML, this analysis has been revisited and updated (see Figure 1); interestingly, the relationships noted in earlier years appear to be enduring, suggesting some genuine underlying meaning. Base data come from train operators' accounts and summary data on train operator performance published by ORR (2007); these are brought together by TAS (2008). The data used have taken fares

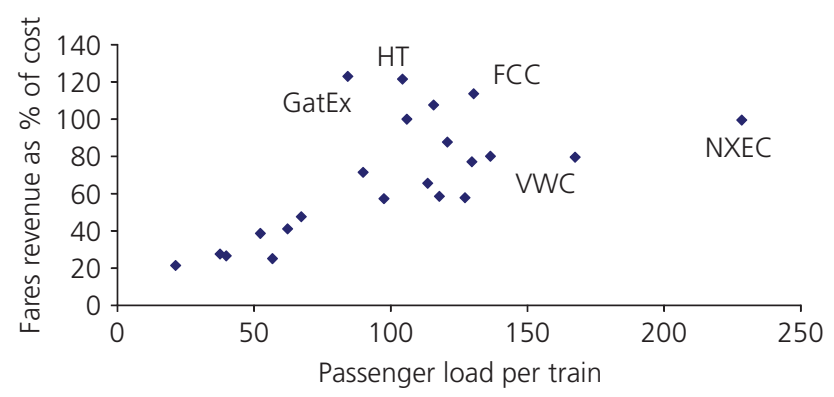

Figure 1. Train operator profitability in Britain by trainload, 2006-2007. Abbreviations refer to specific train operators referred to in the text. $R^{2}=0.92$; estimate of passenger load coefficient 3.52 ( $t$ score 0.53 ); 17 degrees of freedom. Source of underlying data: TAS (2008). GatEx, Gatwick Express; HT, Hull Trains; FCC, First Capital Connect; VWC, Virgin West Coast; NXEC, National Express East Coast 
revenue as the primary indicator of income; some train operating companies (TOCs) gain non-trivial other income through activities such as car parking, property rental income and/or undertaking maintenance work for other TOCs, but these are arguably a function of the current organisational arrangements, and not the underlying profitability of a type of operation. The ECML franchise is thought to make a profit of $£ 30$ million a year from various subsidiary income streams.

Although costs are profoundly affected by train length, this is (or, at least, should be) a function of passenger demand; moreover, costs do not rise linearly with train length, as some (e.g. timetabling, driver) costs are fixed by train path. Average train load is also affected by the number and type of trains run, which are included in the franchise specification. However, there is less regulation of the detail of InterCity services (on the basis that these are subject to greater commercial pressures anyway), so this is unlikely to be a factor explaining the financial performance of ECML.

\section{Implications for rail profitability}

\subsection{Implications for rail profitability in Britain}

Break-even occurs when fares revenue equals operating costs. In Britain in 2006-2007, as Figure 1 shows, this occurred at approximately 160 passengers per train. This apparently represents an improvement on the analysis undertaken of 2000-2001 data, when the figure was around 200 passengers. Part of this change represents a genuine improvement in rail industry economics arising from the increase in the numbers of trains run (on broadly the same network) to accommodate an increased number of passengers. However, part of this improvement is illusory, as government is now channelling additional funds (of around $£ 3.5$ billion per annum. (ORR, 2007) directly to Network Rail, in respect of the infrastructure. These extra funds are both in order to eliminate capacity bottlenecks, and in order to make good shortfalls in maintenance and renewal liabilities associated with the regulatory asset base. Nevertheless, this does give some indication of the trainload required for profitability: above this level, economies of density enable higher profit to be made, while below it the economies of density are simply not strong enough.

When rail scheme business analysis is undertaken, it is usual to estimate transport benefits in the conventional terms of time savings, environmental benefits and the like. Depending upon the level of road congestion relief, total societal benefits in Britain as shown in full demand modelling exercises typically lie in the range three to five times the revenue. That implies that the socially necessary trainload requirement is in the range $1 / 3$ to $1 / 5$ of the marginally profitable trainload - that is, between 55 and 30 passengers per train in 2006-2007. However, a number of British train operators struggle to achieve an average of 55 passengers per train (thus questioning the economic value of the poorestperforming train services), although the regional operators that do struggle tend to include peak urban commuter operations, for which the socio-economic benefits would be at the higher end of the range. Rail's ability to support sustainable urban form, and any consideration of wider economic benefits such as agglomeration, are also excluded from these calculations, although they would (of course) be relatively limited by definition if the number of passengers is reflected in low trainloads. Some rail operations may therefore be only marginally valuable even when social benefits are taken into account.

These figures are, of course, context-dependent. Patterns of travel and social activity vary by country, and Britain has a particularly high proportion of office-based service sector work. While this is particularly amenable to be served by rail, it does lead to very peaky demand (some lines in Britain have hourly peak demand 12 times the level of interpeak demand), which leads to inefficient resource utilisation.

Second, the British government specifies a train service for each franchised area, including times of first and last trains. Services, while not generally of the Swiss Taktfahrplan regularity, are typically hourly or more frequent throughout the day and evening, in order to provide a high level of mobility. However, a requirement to run trains $24 \mathrm{~h}$ per day, or for a longer period on Sundays, would impact on these calculations, and any international comparison should take such factors into account.

\subsection{Implications by time of day}

While it is widely understood that quiet off-peak services are unlikely to be profitable, peak rail economics are often misunderstood in practice. Full peak services do not necessarily imply profitable operation. Peak train operation is associated with a number of costs which are irrelevant for the majority of the day. For instance, ticket office and platform staffing has to be enhanced for the peaks, and some station platforms may only be required for the peaks. Trains may only make one useful trip in each peak, with their time-based leasing costs needing to be wholly supported by the passengers carried on these two trips. In one extreme case, London's Cannon Street station is primarily a peak-only facility, but the opportunity costs of the real estate possibilities of such a prime site in the City of London are enormous. Nevertheless, the social benefits (time-saving, road congestion relief etc.) of the high level of peak demand shown in Figure 2 are enormous, and provide the economic justification for government support to rail services.

Commercially-confidential indicative analysis (e.g. from detailed station entry counts) suggests that peak operations require $75 \%$ of daily costs to achieve $60 \%$ of revenues; this would imply a peak break-even load of 200 passengers. In contrast, offpeak operations take $40 \%$ of revenues with perhaps only $25 \%$ of total costs, which implies a break-even of only 100 passengers. The real interest is in the peak additional train, whose costs are only spread between the passengers of one outward and one return journey per weekday. This requires $100 \%$ of costs to be met by peak passengers, who typically provide $60 \%$ of revenues; that implies a break-even trainload of 266 passengers, or most of the entire seating capacity 
Estimating the profitability of the British

east coast main line

Harris

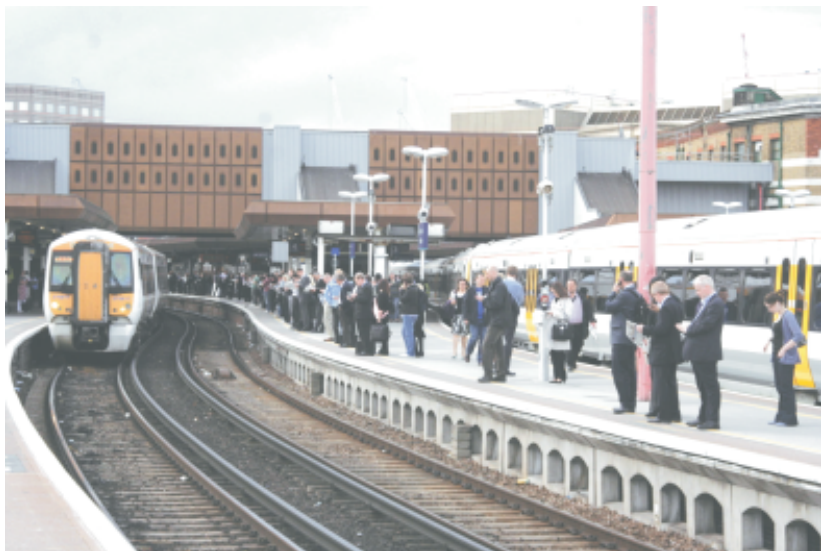

Figure 2. Peak passenger demand at London Bridge: socially beneficial if not strictly profitable

of a four-car train for its entire journey. That analysis reaches similar conclusions from aggregate data as reported in practice by commuter train operator $\mathrm{c} 2 \mathrm{c}$ : the costs of the marginal peak fourcar trainset require it to be fully occupied from the first station on the route (Shoeburyness) to the London terminus at Fenchurch Street. Although $\mathrm{c} 2 \mathrm{c}$ is particularly dominated by commuting movements, with half of its train fleet rested in sidings between the weekday peaks, its ability to support the function and form of the City of London means that its social benefits are extremely high and may well justify this type of operation.

\subsection{Implications by type of train operator}

Even a simple relationship of the form $y=m x$ as shown in Figure 1 to explain profitability in terms of trainload gives a very high $R^{2}$ value of 0.92 , but two issues are immediately apparent. Several train operators lie substantially above the line, while the two primary InterCity operators (National Express east coast (NXEC) and Virgin west coast (VWC)) lie below it.

Of the train operators lying above the line, there are explanations immediately available for most of them. Gatwick Express (GatEx) is an airport shuttle service with particularly high fare levels (typically $£ 0 \cdot 45$ per passenger-mile, compared to $£ 0 \cdot 16$ per passenger-mile for all other train operators). Obviously, for a given number of passengers, much higher fare levels would be expected to lead to higher profitability.

Hull Trains (HT) also shows a performance substantially better than would be expected, but again there is a clear reason. This company runs an 'open-access' operation, in which it has no formal relationship with the government, and is therefore able to be completely commercially independent. However, it also means that it is not responsible for the day-to-day operation of any stations, while (perhaps most significantly of all) it pays only marginal (as opposed to average) track access costs to infrastructure owner Network Rail. These marginal rates are approximately $10 \%$ of the price of full track access costs, which typically constitute $40 \%$ of TOC costs, so that the break-even of openaccess operators is $(1-0 \cdot 36) \times 160$, or around 100 passengers.

FCC (First Capital Connect, comprising the historic Thameslink route (Bedford-Brighton) plus Great Northern services) also has higher-than-expected profitability arising from the one-person operation of many trains. It is also the secondary user of many stations, as opposed to being the 'station facility owner', which might be expected to lead to a greater degree of management costs. Lastly, it is worthy of note that the Thameslink route runs almost $24 \mathrm{~h}$ per day, which could lead to lower marginal train operating costs and (if warranted by demand to the airports served) higher profitability.

The question then turns to the two InterCity operators lying below the line. Virgin's west coast franchise (VWC) includes key services between London and Birmingham, Manchester and Glasgow, in a similar operation to those on the east coast main line. The data therefore tend to suggest that there might be additional costs associated with true long-distance operation. These costs could include:

(a) enhanced station facilities (e.g. business lounges)

(b) higher track access costs (sustained high-speed running leads to greater track wear and tear)

(c) higher train operating costs (provision of a staffed buffet, baggage vehicle, and fuel/electricity consumption at higher speeds)

(d) higher safety standards (e.g. there are restrictions on the number of passengers permitted to travel in the leading vehicle of trains).

Although higher speeds are of course likely to make the railway more competitive vis-à-vis other modes, and hence to increase the potential revenue, the above factors suggest that the cost base may be substantially higher than for conventional rail.

Reworking the analysis of Figure 1 to exclude the high-speed operations of VWC and NXEC gives a higher $R^{2}$ figure of 0.95 , and a lower break-even load for the profitable operation of conventional rail of 150 passengers. Break-even levels for differing levels of assumed socio-economic benefit fall into a range 30-50.

However, an alternative (part-)explanation for the apparently poor performance of the two long-distance train operators could be a function of their fares policy. Business fares on these routes are particularly high (for instance, the Manchester Chamber of Commerce made an official complaint a few years ago regarding peak fares between London and Manchester, which were by then $£ 247$ for a fully flexible standard-class return). Nevertheless, these train operators also offer extremely cheap book-ahead fares. A $£ 20$ return London-Edinburgh, for instance, works out at only $£ 0.025$ per mile (compared to a British average fare of around $£ 0 \cdot 16$ ). In chasing market share, are these operators underpricing? Or are such low fares actually necessary to attract 
passengers who really do have such low willingness to pay, because the market simply is not large enough to provide further demand at average fares?

This highlights the fact that a better determinant of income is not simply how many passengers ride each particular train but how much they contribute in fares between them. As average fares as well as trainloads are known from official figures, this fares yield/ mile has been calculated (see Figure 3). However, as indicated by the earlier comments about marginal passengers being attracted by lower fares, there is no reason to suspect that the relationship between income and profitability is a straight-line one; indeed, one might reasonably expect diminishing returns to set in, and a curved trend line has been hypothesised. Otherwise, higher loads might simply be achieved by selling tickets at such low prices that marginal operating costs were not covered, while passengers' expectations of fares were reduced to a level which is unrealistic and unsustainable in the longer term. Instead, the experience here is that the rail market in this franchise cannot be grown sufficiently to support the revenue growth required by the bids.

Similar comments about the relative position of train operators on this graph can be made as with Figure 1, although one additional point is worthy of note: SET and a number of the other commuter-dominated TOCs fall below the line. Their poorerthan-expected performance is a result of costs being higher through factors including

(a) a greater-than-average number of staffed stations (open access operators merely pay a station access charge as a contribution towards the costs incurred by the main station facility operator)

(b) greater temporal peakiness leading to a disproportionate quantity of assets (e.g. station, rolling stock) to be maintained.

\subsection{Implications for the east coast main line}

The final focus of this analysis is to return to the ECML. The dotted line in Figure 3 indicates a hypothetical trend line to fit the data, although it should be noted that NXEC still falls slightly

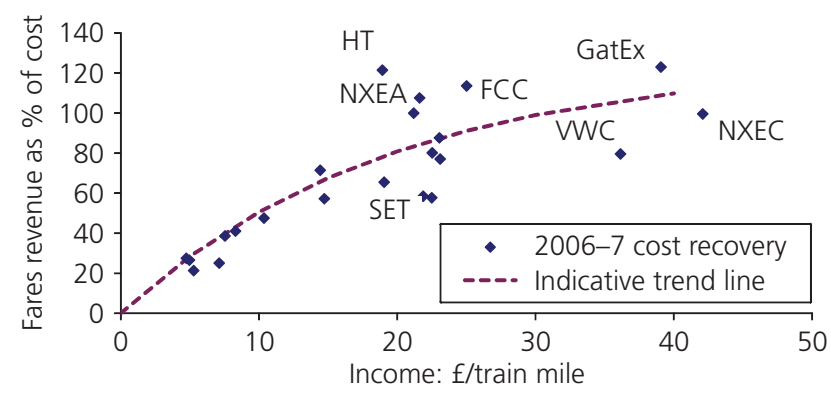

Figure 3. Train operator profitability in Britain by income, 2006-2007. Trend line shown notionally, as specific functional form not intuitive. Source of underlying data: TAS (2008) below this. However, if (from an economic perspective as indicated in the graph) one only expected the fares revenues from this franchise to exceed operating costs by $5-10 \%$, then it would imply that the potential premium payment is rather small. Even allowing for a $5 \%$ profit margin for the management and some margin for risk to offset the profitable other income streams, a premium payment might therefore be of the order of $10 \%$ of the franchise turnover $(10 \%$ underlying rail operating profit margin $+5 \%$ other income, less $5 \%$ profit element taken by the franchisee). In 20062007 , the NXEC franchise recorded a turnover of $£ 531$ million, implying a potential premium of $£ 50$ million per annum. This is rather higher than the premium actually paid that year, but the first years of franchises often include an allowance for investment in the business and similar costs; the $£ 50$ million value is, however, very similar to the actual premium paid in 2007-2008, but future payments up to $£ 200$ million per annum were previously promised for 2013 onwards. These might have been justified either on traffic growth due to underlying economic conditions, or reductions in costs (perhaps from economies of scale). As we have seen, however, the former of these may be impossible if the market simply is not large enough, while the latter may be impossible owing to the high-speed nature of the service.

The actual franchise did make a profit (of $£ 23$ million) in 20062007 (a margin of about 4.5\%), but this included the impacts of secondary revenues (including car parking). Primary revenues from fares, on the other hand, at $£ 492$ million, fell slightly short of the operating costs of $£ 508$ million. Although some costcutting measures are no doubt possible, the franchising system encourages management to minimise these; nevertheless, more were tried by NXEC in late 2008. Moreover, both cost-cutting in areas such as catering and tariff increases in car-parking have the potential to reduce rail transport revenues in the medium term, and therefore may not actually be worthwhile.

As evidence from the real world suggests that this level of franchise premium is not sustainable, it can be deduced that either there are indeed operational costs associated with high-speed rail and/or such large revenues cannot be sustained. The discussion above suggests that both of these hypotheses are reasonable. However, the detailed implication of all that is that the real level of premium which can be extracted from this particular franchise may be relatively small. While both Sea Containers and National Express may have had their corporate reasons for bidding high, this analysis suggests that neither bid was realistic. Premia values rising from $£ 0 \cdot 5$ million per week to $£ 1$ million per week over the existing franchise period appear to be much more sustainable than the premia promised, and it would be advisable for both bidders and the government to understand this, if further franchise failures are to be avoided.

\section{Conclusion}

An analysis of train operator data available in Britain has enabled a preliminary estimation of the trainload required to provide profitable operation ( $\approx 160$ passengers). Through inference, it has also been possible to indicate the (lower) trainloads required for 
Transport

Volume 166 Issue TR3
Estimating the profitability of the British

east coast main line

Harris operation both for open-access operators, and to satisfy appropriate levels of social benefit. These trainload estimations should give some guidance to transport planners and policy makers when looking to deliver sustainable public transport.

There is evidence that the two main long-distance train operators in Britain are less profitable than one might expect, and therefore less able to provide large premia, for reasons which relate to the attributes of those services. This is likely to have more general applicability in other countries. These attributes include the higher costs associated with the operation of high-speed services, and lower marginal revenues reflecting the lower willingness-topay of the marginal passenger. Application of the analysis to the British east coast main line franchise, which has been subject to a number of over-confident franchise bids, suggests that the premia suggested by those bidders did not reflect the underlying economics of the line. A much lower level of franchise premia based on the higher costs of high-speed operation would have been more appropriate, and this understanding should be helpful to train operators worldwide.

\section{Acknowledgements}

Thanks are due to the authors's Railway Consultancy colleagues for clarification of the issues, and to anonymous referees of earlier drafts of this paper for their helpful comments.

\section{REFERENCES}

DfT (Department for Transport) (2012) http://www.dft.gov.uk/ pgr/rail/passenger/franchises/icecf1/nxecawardedcontract (accessed June 2012).

Gourvish T (2008) Britain's Railways 1997-2005: Labour's Strategic Experiment. Oxford University Press, Oxford, UK. Harris NG (1997) Analysis of the Subsidies Bid for British Rail Passenger Franchises. PTRC 25th European Transport Forum, Uxbridge, UK.

Harris NG and Godward EW (1997) The Privatisation of British Rail. Railway Consultancy, London, UK.

ORR (Office of the Rail Regulator) (2007) National Rail Trends. ORR, London, UK.

TAS (Transport Advisory Services) (2008) Rail Industry Monitor. TAS, Skipton, UK.

\section{WHAT DO YOU THINK?}

To discuss this paper, please email up to 500 words to the editor at journals@ice.org.uk. Your contribution will be forwarded to the author(s) for a reply and, if considered appropriate by the editorial panel, will be published as a discussion in a future issue of the journal.

Proceedings journals rely entirely on contributions sent in by civil engineering professionals, academics and students. Papers should be 2000-5000 words long (briefing papers should be 1000-2000 words long), with adequate illustrations and references. You can submit your paper online via www.icevirtuallibrary.com/content/journals, where you will also find detailed author guidelines. 